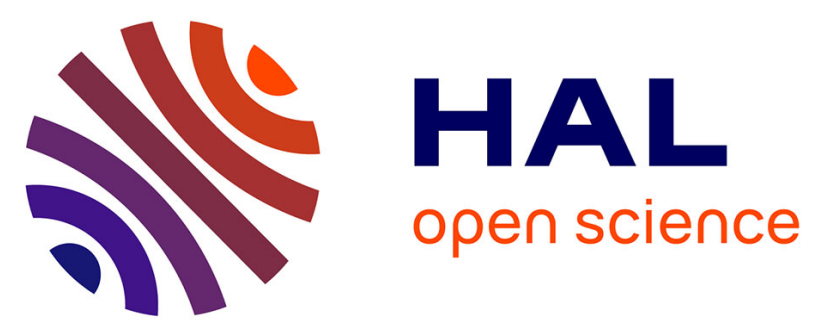

\title{
18th ICPR paper: INDUSTRIAL PERFORMANCE MEASUREMENT: AN APPROACH BASED ON THE AGGREGATION OF UNIPOLAR OR BIPOLAR EXPRESSIONS
}

Lamia Berrah, Gilles Mauris, François Vernadat

\section{To cite this version:}

Lamia Berrah, Gilles Mauris, François Vernadat. 18th ICPR paper: INDUSTRIAL PERFORMANCE MEASUREMENT: AN APPROACH BASED ON THE AGGREGATION OF UNIPOLAR OR BIPOLAR EXPRESSIONS. International Journal of Production Research, 2006, 44 (18-19), pp.4145-4158. 10.1080/00207540600786699 . hal-00512918

\section{HAL Id: hal-00512918 https://hal.science/hal-00512918}

Submitted on 1 Sep 2010

HAL is a multi-disciplinary open access archive for the deposit and dissemination of scientific research documents, whether they are published or not. The documents may come from teaching and research institutions in France or abroad, or from public or private research centers.
L'archive ouverte pluridisciplinaire HAL, est destinée au dépôt et à la diffusion de documents scientifiques de niveau recherche, publiés ou non, émanant des établissements d'enseignement et de recherche français ou étrangers, des laboratoires publics ou privés. 


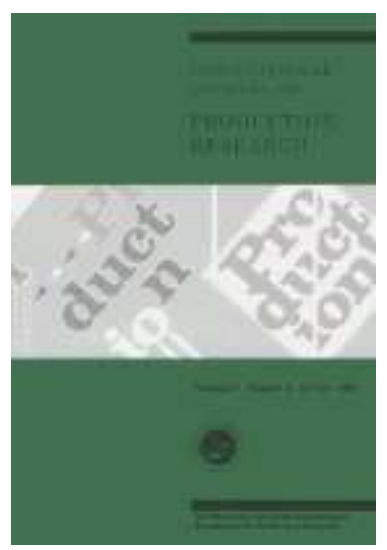

\section{8th ICPR paper: INDUSTRIAL PERFORMANCE MEASUREMENT: AN APPROACH BASED ON THE AGGREGATION OF UNIPOLAR OR BIPOLAR EXPRESSIONS}

\begin{tabular}{|r|l|}
\hline Journal: & International Journal of Production Research \\
\hline Manuscript ID: & TPRS-2005-IJPR-0545.R1 \\
\hline Manuscript Type: & Original Manuscript \\
\hline Author: & 07-Apr-2006 \\
\hline Complete List of Authors: & $\begin{array}{l}\text { Berrah, Lamia; ESIA - Université de Savoie, LISTIC } \\
\text { Mauris, Gilles; ESIA - Université de Savoie, LISTIC } \\
\text { Vernadat, Francois; European Commission, Unit B2, } \\
\text { Interoperability, Architecture and Methodologies }\end{array}$ \\
\hline Keywords: & $\begin{array}{l}\text { PERFORMANCE MEASURES, PERFORMANCE ANALYSIS, } \\
\text { MANUFACTURING SYSTEMS ENGINEERING, MANUFACTURING } \\
\text { MANAGEMENT }\end{array}$ \\
\hline Keywords (user): & $\begin{array}{l}\text { PERFORMANCE MEASUREMENT SYSTEMS, INDUSTRIAL } \\
\text { PERFORMANCE AGGREGATION }\end{array}$ \\
\hline \multicolumn{2}{|l}{} \\
\hline
\end{tabular}

\section{ScholaronE \\ Manuscript Central}




\title{
INDUSTRIAL PERFORMANCE MEASUREMENT: AN APPROACH BASED ON THE AGGREGATION OF UNIPOLAR OR BIPOLAR EXPRESSIONS
}

\author{
L. Berrah ${ }^{1}$, G. Mauris ${ }^{1}$, F. Vernadat ${ }^{2}$ \\ ${ }^{1}$ LISTIC, ESIA-Université de Savoie, BP 806, F-74016 Annecy cedex, France \\ ${ }^{2}$ LGIPM, ENIM-Université de Metz, Ile du Saulcy, F-57045 Metz cedex 1, France
}

\begin{abstract}
Industrial performance concerns numerous criteria, often in interaction and of complex nature, not related to one elementary measure. Performance Measurement Systems (PMSs) have been developed to support decision-making for reaching the objectives and launching adequate action plans. PMSs provide thus performance expressions which identify objective satisfaction degrees. Two kinds of performance expressions are useful in industrial problems, according to the scale (unipolar, bipolar) that is used for their definition. Moreover, these expressions generally have to be synthesized for global control purposes, determining an overall performance raises the issue of performance aggregation. To address such an aggregation issue, adequate multi-criteria methods need to be implemented. Most of the approaches proposed in the literature either do not provide explicit mechanisms, or rely on too simple methods. This paper deals with the definition of a performance combination based on mathematical tools, especially the generalized Choquet integral to take into account on the one hand criteria interactions and on the other hand both unipolar and bipolar scales. An application to a PMS for the service rate of a SME producing kitchen elements is used to illustrate the approach.
\end{abstract}

\section{Keywords}

Performance Measurement Systems (PMSs), Industrial performance aggregation, unipolar and bipolar performance expressions, 2-additive Choquet integral. 


\section{INTRODUCTION}

The field of design, implementation and use of Performance Measurement Systems (PMSs) emerged about ten years ago [1] as the instruments to support decision-making in a continuous improvement process [2] [3] [4]. PMSs take part in a wider company information and decision system, which in particular includes strategic objectives setting. From a global point of view, a PMS can be seen as a multi-criteria instrument, made of a set of performance expressions, physical measures as well as performance evaluations, to be consistently organized with respect to the objectives of the company. More particularly, these measures are generally aimed at controlling business processes by evaluating the satisfaction of the objectives associated to them [5] [6]. Then, in order to support decision-making, a set of performances has to be processed for comparing the different process states encountered. To get an overall performances, aggregating the elementary performances is an useful approach [7]. More precisely, the major problems in the design of PMSs concern, on the one hand, the break-down of the global objective considered into elementary ones along organizational levels (strategic, tactical or operational) and, on the other hand, the aggregation of the elementary performance expressions to consolidate the value of the global one [7] [8].

Generally speaking, as shown by the review of the performance measurement literature (see [7]), information aggregation is not considered as a central a priori problem for PMS design, but as an a posteriori one once performance expressions have been selected and defined. Indeed, nearly all the proposals are in fact frameworks for linking strategic objectives, structuring tactical and operational criteria affecting them. Most of the contributions focus thus on the way of selecting the dimensions, the levels and the criteria to be considered for company performance definition. The research result is given under the form of logical breakdown links between the criteria involved, the decisions being taken from the associated 
structured multiple performance expressions. In addition, in a few research works [9] [2] [10] [11], the links are quantified by weights, and an aggregated performance expression is proposed as a weighted mean of the elementary ones. But, weights are generally determined regardless of the performance expressions that are generally heterogeneous physical measures. This can lead to commensurability issues. Moreover, the proposed break-down structures consider only independent contributions of criteria and not interactions between them, except for two recent proposals [10] [11].

To have an explicit formalization of performance aggregation, the paper considers the aggregation problem as related to the definition of a function combining elementary performance expressions in order to determine the expression of the overall performance [12]. This leads to two main problems: defining commensurate elementary performance expressions and determining combination function parameters. The definition of elementary performance expressions is defined not only on a unipolar scale but also on a bipolar one. Indeed, positive and negative expressions are useful for industrial control to perform adequate feedback control. For the combination function, the 2-additive Choquet integral is considered because it takes into account horizontal interaction (i.e. mutual interaction of performance terms). The associated parameters are extracted from the decomposition of the overall information into elementary ones according to mangers' expertise.

The paper is organized as follows. Section 2 presents the characteristics of performance expressions and the requirements for performance aggregation. In this sense, some methodological considerations are drawn in section 3. Section 4 illustrates the approach on a practical case study from a manufacturing company producing kitchen and bathroom elements. Some concluding remarks and emerging problems are finally outlined. 


\section{INDUSTRIAL PERFORMANCE MEASUREMENT FRAMEWORK}

Broadly speaking, a performance expression is associated to a given objective, and is related to its satisfaction degree. Naturally, objectives are defined at different company levels, and therefore the performance expressions are of different nature. They are in particular overall when the objectives are at the highest decision level and elementary when they are at the lowest levels. The performance expression role is devoted to the PMSs, for which there are two basic ways to express performance.

- The direct way: it consists in evaluating measures that represent the actual states of the considered activities, with their objectives specifying the expected states. The measures can be simple physical observations acquired in the form of single values (e.g. number of bad parts, line flow time), or obtained from the processing of several measures (e.g. mean number of bad parts per week, mean line flow time per day). The comparison is usually a ratio, a relative difference, or a normalized distance.

- The indirect way: it consists in combining several elementary performance expressions to determine the global one without considering a single measure for the overall entity. This post-taylorian situation occurs when the measure related to the global objective cannot be obtained due to two main reasons. The different elementary measures do not have the same dimension (e.g. skillfulness defined on the basis of know-how, working-speed, quality of work and perturbation handling), some being subjective to some extent (e.g. know-how). The semantics of the overall performance must be handled by the combination of its elementary performance components (e.g. overall performance defined by a trade-off between cost, quality and delivery performances). 


\subsection{Direct performance expression based on the measure/objective comparison}

\section{Definition}

Concerning the direct method, the performance expressions returned by the so-called performance indicators result from the straightforward comparison between the objectives and the measures describing the effective process or activity enactment. Hence, the performance expressions can be formalized by the following mapping [12]:

$$
\begin{aligned}
& \mathrm{P}: \mathrm{O} x \mathrm{M} \rightarrow \mathrm{E} \\
& (o, m) \rightarrow \mathrm{P}(o, m)=P
\end{aligned}
$$

$\mathrm{O}, \mathrm{M}$ and $\mathrm{E}$ are respectively the universes of discourse of the set of objectives $\mathrm{O}$, of the set of measures $\mathrm{m}$ and of the performance expressions $P$. The key point in differentiating this kind of performance expression from conventional measurements is the comparison in some sense of the acquired measures with an objective defined according to the control strategy considered. Thus, the mapping $\mathrm{P}$ denotes a comparison operator such as a distance operator or a similarity operator [12].

Therefore, we will not consider the particular case where the mapping $\mathrm{P}$ is not made explicit and the performance expression is not defined on a performance universe having its own dimension, i.e. $\mathrm{E}=\mathrm{M}$. The focus remains on situations for which an explicit comparison between measures and objectives is carried out. From a general point of view, E can be any set, e.g. the set of real numbers or integers. The choice of a specific universe $E$ of performance expressions is ruled by the cognitive efficiency of the control decision-making, i.e. the performance expressions must be useful, relevant, easily readable, understandable, and quickly interpretable by the decision-makers. Thus, the performance criteria being associated to different physical heterogeneous entities (price, size, delay...), a first point is to make them commensurate in some sense. This leads to consider a common shared semantic for the universe E. This is explained hereafter. 


\section{Commensurateness of performance expressions}

One widely used universe of performance is $E=[0,1]$, where 0 means objective not satisfied at all and 1 means objective fully satisfied. Another possibility is to consider a universe $E=[-1,1]$ going from negative value (bad) to positive value (good), including a central neutral value (0). Such a scale is called a bipolar scale. Defining commensurate unipolar or bipolar performance expressions, i.e. having the same meaning for identical values of satisfaction degrees, is not straightforward. For example, 0.8 (respectively -0.4) for quality performance must mean the same thing in performance terms than 0.8 (respectively -0.4) for delivery time performance. As it is not the main concern of this paper, this point is not deeply discussed herein, but general considerations and examples are given associated with adequate references.

The mechanism ensuring the commensurateness is based on the definition by the decisionmakers of two reference values for unipolar expressions, three for bipolar expressions, having a common satisfaction meaning for all the criteria. Generally, the reference values correspond to totally unsatisfactory (-1), neutral (0) and totally satisfactory (1), and they are associated to values of the universe of measures to anchor the comparison between different situations.

For example, let us consider the average delay criterion for a manufacturing company. The objective to attain is $o=0$ hours and the value leading to an absolute non satisfaction is $\bar{o}=48$ hours .Then, for a particular measure $\mathrm{m}$, the unipolar performance expression can be defined by a linear interpolation: $P=\frac{m-\bar{o}}{o-\bar{o}}$, e.g. for $\mathrm{m}=12, P(12)=\frac{12-48}{-48}=0.75$. This approach guarantees the commensurateness for the extreme performance values but only in an approximate way for the others. To go further, all other values have to considered. This being difficult, it is possible to consider a limited set corresponding to situations well known to the decision-maker. It is the spirit of a method called MACBETH (Multi Attractiveness Categorical Based Evaluation Technique) based on the decision-maker's preferences and detailed in [13][14]. 


\section{Unipolar versus bipolar performance expressions}

A natural behavior of decision-makers is to sometimes make a distinction between positive and negative quality of actions. For example, when following a continuous improvement process, the overall performance is expected to be improved (i.e. positive) but it can be steady (i.e. null) or even degraded (i.e. negative). Moreover, some elementary performances can be improved and a few degraded. This leads to consider a bipolar universe $E=[-1,1]$ going from negative value (bad) to positive value (good), including a central neutral value (0). Moreover, a significant interest of bipolar expressions for industrial control is that a direct analogy with closed-loop control systems is highlighted. Indeed, in this view the performance indicator, which provides signed expressions, can be assimilated to the comparator of the control loop, the objective being the set-point. In fact, the bipolar scale has a richer structure but it leads to more complex processing in particular for the aggregation as exposed in section 3.

Indeed, once performance expressions (unipolar or bipolar) have been determined, a coherent control requires a reporting system from lower to higher decisional levels that synthesizes local performance expressions into overall ones. This refers to the indirect way of obtaining performance expressions as a combination of other expressions.

\subsection{Indirect performance expression based on the combination of elementary expressions}

\section{Definition}

Concerning the indirect method, the combination of the performance expressions can be expressed as an operation that synthesizes the elementary performance expressions into a overall one.

Hence, the performance aggregation can be formalized by the following mapping: 


$$
\begin{aligned}
A g: \quad & E_{1} \times E_{2} \times \ldots E_{n} \mapsto E \\
& \left(P_{1}, P_{2}, \ldots, P_{n}\right) \rightarrow P_{A g}=\operatorname{Ag}\left(P_{1}, P_{2}, \ldots, P_{n}\right)
\end{aligned}
$$

$E_{i}$ is the universe of discourse of the elementary performance expressions $P_{i}$ and $E$ is the universe of discourse of the global performance expression $P_{A g}$.

\section{Aggregation operator requirements}

Generally the performance criteria are characterized by subordination as well as horizontal interactions. Furthermore, coalitions or conflicts whole constitute interaction phenomena that may influence the set of performance criteria. Horizontal interactions express coordination links that ensure the coherence of the satisfaction degrees at a given hierarchical level. As pointed out in previous works [8], the conventional weighted mean cannot deal with this latter aspect. It is only well-suited for a tree performance structure composed of independent performance criteria. Therefore, new aggregation functions must be added in order to benefit from this semantic distinction in the relations among criteria: modelling the relative importance of a criterion and its interactions with the other ones.

For instance, operator skilfulness in assembling kitchen elements and element availability at the operators' workstation have a mutual interaction with respect to the average delivery time of kitchen shipment. But the performance structure can be more complex. For example, concerning the service rate, when the average delay of shipments is bad, time between order and product manufacturing is more important than accuracy of shipments, and when the average delay of shipments is good, time between order and product manufacturing is less important than accuracy of shipments.

However, there is a need to make a trade-off between the different interacting performance criteria involved. This leads to consider compromise operators, and thus to disqualify those that model severe or tolerant behaviour (such $t$-norms and $t$-co-norms). In this sense, the operators of the Choquet integral family [15] are interesting as explained in the next section. 
1

\section{METHODOLOGICAL GUIDELINES FOR THE PERFORMANCE AGGREGATION}

As the structures of the unipolar and bipolar scales are not identical (existence of a neutral level), the processing of their values, in particular their aggregation, has to be carried out in slightly different ways.

\subsection{Unipolar performance evaluation aggregation}

The operators of the Choquet integral family are interesting because they cover a lot of generalized mean operators (i.e. those comprised between the min and the max operators). Moreover, they can be written under the form of a conventional weighted mean modified by effects coming from interactions between elementary performance evaluations. Finally, they are coherent with the performance expressions on an unipolar interval scale on the universe $[0,1]$. Therefore, we select this type of combination for performance evaluation aggregation, especially the 2-additive Choquet integral that considers only interactions by pair.

\section{Background on 2-additive Choquet integral}

The 2-additive Choquet integral is based on 2 types of parameters [16].

- The importance of each elementary performance criterion in relation to all the other contributions to the overall performance evaluation by the so-called Shapley parameters $v_{i}$ 's, that satisfy $\sum_{i=1}^{n} v_{i}=1$, which is a natural condition for decision-makers where $v_{i}$ are the weights,

- The interaction parameters $I_{i j}$ of any pair of performance criteria, that range in [-1, 1]; a value of 1 means positive synergy, a value of -1 means negative synergy and a value of 0 means no influence.

The associated aggregation function is given by: 


$$
\begin{aligned}
A g_{C I}\left(P_{1}, P_{2}, \ldots, P_{n}\right)= & \sum_{i=1}^{n} P_{i}\left(v_{i}-\frac{1}{2} \sum_{j \neq i}\left|I_{i j}\right|\right)+\sum_{I_{i j}>0} \min \left(P_{i}, P_{j}\right) I_{i j} \\
& +\sum_{I_{i j}<0} \max \left(P_{i}, P_{j}\right)\left|I_{i j}\right|
\end{aligned}
$$

with the property that $\left(v_{i}-\frac{1}{2} \sum_{i \neq j}\left|I_{i j}\right|\right) \geq 0$.

For example, let us consider two performance criteria $c_{1}$ and $c_{2}$ having as weights $v_{1}=0.4$ and $v_{2}=0.6$ and an interaction $I_{12}=0.4$. Then, for elementary performances $P_{1}=0.8$ and $P_{2}=0.4$ the aggregated performance is $P_{A g}=0.2 \times 0.8+0.4 \times 0.4+0.4 \times 0.4=0.48$. Without the interaction, we would obtain $P_{A g}=0.4 \times 0.8+0.6 \times 0.4=0.56$, i.e. around $15 \%$ of difference.

In fact, the aggregation function is decomposed in a conventional linear part modified by a conjunctive and a disjunctive part. A null $I_{i j}$ implies that no interaction exists; thus $v_{i}$ acts as the weights in a common weighted mean, e.g. $P_{1}=0.8 P_{2}=0.4$ and $P_{1}=0.65 P_{2}=0.6$ lead with the preceding Shapley parameters values to the same aggregated performance $P_{A g}=0.56$. A positive $I_{i j}$ implies that the decision-maker prefers simultaneous high values for $P_{i}$ and $P_{j}$, e.g. for $I_{12}=0.4, P_{1}=0.8 P_{2}=0.4$ leads to $P_{A g}=0.48$ when $P_{1}=0.65 P_{2}=0.6$ leads to $P_{A g}=0.61$. A negative $I_{i j}$ implies that a high value for $P_{i}$ or for $P_{j}$, is sufficient to have a significant effect on the aggregated performance evaluation, e.g. for $I_{12}=-0.4, P_{1}=0.8 P_{2}=0.4$ leads to $P_{A g}=0.568$ when $P_{1}=0.65 P_{2}=0.6$ leads to $P_{A g}=0.521$.

In summary, the $v_{i}$ values are the weights of a combination by the weighted mean when no interaction exists, $I_{i j}$ values performing second order corrections on this weighted mean according to the decision-maker's preferences. 


\section{Aggregation parameter determination}

One important aspect is how to determine the value of the weights and the interactions in a coherent way with the elementary performance expression. In this view, the parameters have to be determined from the aggregation operator expression. One simple approach is to consider particular performance situations, i.e. situations corresponding to so called characteristics vectors composed only with 0 and 1 elementary performance expressions, e.g. $(1,1),(1,0),(0,1)$ for two criteria. Thus, knowing the associated aggregated performance (e.g. $1,0.6,0.8)$ leads to a system of three independent equations with the aggregation parameters as unknowns, i.e.:

$v_{1}+v_{2}=1$

$v_{1}+0.5 . \mathrm{I}_{12}=0.6$

$v_{2}+0.5 . I_{12}=0.8$

The aggregation parameters are then deduced by solving the system. For the considered example, we obtain: $v_{1}=0.4 ; v_{2}=0.6 ; \mathrm{I}_{12}=0.4$.

Furthermore, having more situations than the minimum required to solve the equation system can allow to verify the coherence of the manufacturing manager's knowledge about the considered situations. On the other hand, if the direct expression of the global performance associated to the elementary performance vectors is too difficult for the manufacturing manager to state, asking him to provide magnitude order of the difference of performance values between the different situations can also permit to determine the parameters as proposed by the Macbeth method [14]. In fact, the approach consists in a quantified refinement of the logical objective decomposition often provided under the form of a tree structure (see Figure 1).

Note also that the obtained parameters represent the decision-maker's preferences and not directly the physical relationships between the variables. In fact, the former depend on the latter but they are not equivalent. Indeed, the decision-maker behavior can change according 
to the company context, as opposed to the variable relationships that are constant (e.g. the productivity decreases with the number of breakdowns).

\subsection{Bipolar performance evaluation aggregation}

\section{Introduction}

In this case, it is important to derive aggregation operators taking into account the dichotomy between positive and negative values [17]. The Choquet integral, which is invariant to a shift of the scale, is insensitive to the neutral level, and thus cannot serve directly for this purpose. However, one can add some sensitivity by a simple symmetrization of the Choquet integral around 0 (the symmetric Choquet integral is also known as the Sipos integral). Indeed, the [0, 1] unipolar scale can thus be seen as a bipolar scale, with for instance the neutral value 0.5 . In this view, by making a linear transformation of unipolar expression, a bipolar expression can be obtained. This gives the advantage to highlight the neutral level for instance in a continuous improvement process, but the aggregation of negative and positive values follow the same behaviour.

Another approach consists in computing the positive expressions and the negative expressions separately by two different Choquet integrals. This enables to model different behaviors of the decision-maker when faced with positive and negative performance expressions. But a thorough study of bipolar scales [17] leads to the fact that the two preceding approaches failed to represent situations such as the one mentioned before: e.g. when the average delay of shipments is bad, time between order and product manufacturing is more important than accuracy of shipments, and when the average delay of shipments is good, time between order and product manufacturing is less important than accuracy of shipments.

Therefore, the notion of bi-capacity has been proposed to resolve this problem [18]. Roughly speaking, a bi-capacity encodes the performance expressions of all possible combinations of 
positive and negative performances, so that it is able to represent complex interaction phenomena. Furthermore, the aggregation operator should enable the computation of an overall performance of any performance vector (compose of positive and negative values). In this view, Grabisch has introduced the so-called generalized Choquet integral [19].

\section{The 2-additive generalized Choquet integral}

The 2-additive generalized Choquet integral is always based on two types of parameters: the importance and interaction parameters. But this time, they are defined by pieces defined by the signs of the performance expressions:

- $v_{i, 8}$ the importance of criterion $i$ when the values of all criteria are positive,

- $v_{\varnothing, i}$ the importance of criterion $i$ when the values of all criteria are negative,

- $I_{i, \delta}$ the interaction of $i$ and $j$ when the values of all criteria are positive,

- $I_{\varnothing, i j}$ the interaction of $i$ and $j$ when the values of all criteria are negative,

- $I_{i, j}$ the interaction between $i$ and $j$ when the value of $i$ is positive, the value of $j$ negative, and the others neutral.

The associated aggregation operator is given by:

$$
\begin{aligned}
A g_{C I}\left(P_{1}, \ldots, P_{n}\right) & =\sum_{i \in N^{+}} P_{i}\left[v_{i, \varnothing}+\frac{1}{2}\left(\sum_{j \in N^{+} \backslash i} I_{i, j}-\sum_{j \in N^{-}} I_{i, j}-\sum_{j \neq i} I_{i j, \varnothing}\right)\right] \\
& +\sum_{i \in N^{-}} P_{i}\left[v_{\varnothing, i}+\frac{1}{2}\left(-\sum_{j \neq i} I_{i, j}+\sum_{j \in N^{+}} I_{\varnothing, i j}-\sum_{j \in N^{-} \backslash i} I_{\varnothing, i j}\right)\right] \\
& +\sum_{\substack{i j \in N^{-} \\
\varnothing, i j}} \min \left(P_{i}, P_{j}\right)+\sum_{i j \in N^{+}} I_{i j, \varnothing} \min \left(P_{i}, P_{j}\right) \\
& +\sum_{\substack{i \in N^{+} \\
j \in N^{-}}} I_{i, j} \max \left(P_{i}+P_{j}, 0\right)
\end{aligned}
$$

where $N^{+}$and $N^{-}$are the respectively the sets of criteria having positive performance values and negative performance values. This expression is in the same line as equation (1) except 
for the last term that allows to take the interaction between positive and negative performance values into account.

For example, let us consider two performance criteria $c_{1}$ and $c_{2}$ having as parameters: $v_{1, \varnothing}=0.2 ; v_{2, \varnothing}=0.4 ; v_{\varnothing, 1}=0.6 ; v_{\varnothing, 2}=0.8 ; I_{12, \varnothing}=0 ; I_{\varnothing, 12}=0$ and $I_{1,2}=0.4$. Then, for the elementary performances $P_{1}=0.8$ and $P_{2}=-0.4$, the aggregated performance is $P_{A g}=0 \times 0.8+0.6 \times-0.4+0.4 \times(0.8-0.4)=-0.08$. For $P_{1}=0.2$ and $P_{2}=0.2$, we obtain $P_{A g}=0.2$. This result illustrates the fact that in this case the decision-maker prefers not having one negative performance value.

Nevertheless, this aggregation function is more complex and requires much more effort to be determined. Nevertheless, in the same spirit as the unipolar case, the parameters can be determined by the decision-makers' overall evaluations of ternary performance vectors $\left(1_{A},-1_{B}, 0_{-A \cup B}\right)$ ( $A$ and $B$ are disjoint subsets of the performance criteria), and by solving the corresponding equation systems.

\section{APPLICATION}

The case study concerns a SME producing kitchen, bathroom and storing space elements. The overall objective of the company is to continuously increase the profit margins. In this sense, knowing that the company wants to improve its performance in terms of delay, the focus is more particularly on the objective related to the service rate. The aim of this study is not to confine decision-makers to a narrow choice of performance indicators to assess and control their system, but to make a compromise among a limited set of relevant but conflicting performance evaluation criteria. The approach suggested is therefore: first to carry out a topdown objective break-down, to define elementary performance evaluations and to extract weights and interactions in a coherent way, and then to implement a bottom-up performance aggregation mechanism. 
The bipolar performance expressions are illustrated with two examples: (1) when symmetric Choquet integral can be applied, i.e. no interaction between the positive and negative performances, and (2) when generalized Choquet integral has to be applied, i.e. interaction between positive and negative values exists.

\subsection{Objective break-down}

The first stage consists in breaking down the top-management strategic objectives according to the various levels of the hierarchical decisional structure of the company (i.e. the organization chart). Figure 1 provides a partial break-down of the strategic objective related to the service rate into tactical objectives and basic criteria to be used to assess operational objectives. The service rate objective is declined into three tactical independent objectives having the same importance and five operational ones, having different weights and interactions as indicated in Tables 3 and 4.

For the sake of conciseness, the paper only details the break-down of tactical criterion time between order and product manufacturing (TBOP) into operational indicators, but the same procedure can be applied for the other tactical criteria.

Figure1. Performance structure of the strategic service rate objective

\subsection{Operational performance measurements and evaluations}

The operational performance measurement involved in the tactical criterion time between order and product manufacturing are summarized in Table 1.

Table 1: Operational performance measurements 
In order to obtain performance evaluations from the performance measurements, the production manager has been asked about the objectives to attain at the operational level and about the performance evaluations of the current situation. This information is summarized in Table 2. For other performance measurement values, the performance evaluations are then computed by making a linear interpolation. Thus, commensurate performance evaluation is obtained in a $[-1,1]$ linear scale for all the operational criteria.

\section{Table 2: Operational performance measurements and evaluations}

\subsection{Case of symmetric Choquet aggregation}

\section{Aggregation parameters}

As mentioned in section 3 , to determine the aggregation operator parameters, the overall performance has to be known for independent vectors of elementary performance evaluations. Using this approach (inspired from the Macbeth method [6]) leads to have consistency between the elementary performance evaluations and the aggregation coefficients (gathered in Tables 3 and 4).

Table 3: The weights of the different operational criteria

Table 4: The interactions between the operational criteria versus the tactical objective TBOP

Thus, in summary, the Choquet integral aggregation parameters are $v_{1}=0.20, v_{2}=0.35$, $v_{3}=0.35, v_{4}=0.10$, and $I_{12}=0.07, I_{13}=0.13, I_{14}=0.07, I_{23}=-0.08, I_{24}=-0.06, I_{34}=0$. 
Example of performance aggregation

According to the equation and to the parameters determined previously, the 2-additive Choquet integral (Eq. 1) becomes for the considered case:

${ }^{A g} C I\left(P_{1}, P_{2}, P_{3}, P_{4}\right)=P_{A g}=0.065 P_{1}+0.245 P_{2}+0.245 P_{3}+0.035 P_{4}$
$+0.07 \min \left(P_{1}, P_{2}\right)+0.13 \min \left(P_{1}, P_{3}\right)+0.07 \min \left(P_{1}, P_{4}\right)+0.08 \max \left(P_{2}, P_{3}\right)+0.06 \max \left(P_{2}, P_{4}\right)$

Thus, for the current situation $P_{1}=-1, P_{2}=-0.1, P_{3}=0.50$ and $P_{4}=0.20$ where the skilfulness objective is totally unsatisfied, we obtain $\mathrm{P}_{\mathrm{Ag}}=-0.18$ (if the mutual interactions had been ignored, the result would be $\left.\mathrm{P}_{\mathrm{Ag}}=+0.04\right)$.

Then, an action is carried out on skillfulness and a new situation is observed with $\mathrm{P}_{1}{ }_{1}=0.2$, $\mathrm{P}_{2}^{\prime}=-0.1, \mathrm{P}_{3}=0.50$ and $\mathrm{P}_{4}=0.20$, which leads to $\mathrm{P}^{\prime}{ }_{\mathrm{Ag}}=0.20$. Therefore, an action on bottleneck productivity is done: a machine is added, leading to $\mathrm{P}{ }_{1}=0.2, \mathrm{P}{ }_{2}=0.4, \mathrm{P}{ }_{3}=0.50, \mathrm{P}{ }_{4}=0.20$ and P" ${ }_{\mathrm{Ag}}=0.36$, that constitutes a significant improvement.

\subsection{Case of generalized Choquet aggregation}

In this section, the aggregation between the tactical level and the strategic level is considered. Indeed, the service rate performance is defined by the aggregation of the average delay of shipments, the time between order and product manufacturing and the accuracy of shipments. These three criteria have different relative importance and moreover the following rule holds: when the average delay of shipments is bad, time between order and product manufacturing is more important than accuracy of shipments, and when the average delay of shipments is good, time between order and product manufacturing is less important than accuracy of shipments.

These rules can be translated in the following generalized Choquet integral aggregation parameters: 
$v_{1, \varnothing}=0.3 v_{\varnothing, 1}=0.3 v_{2, \varnothing}=0.1 v_{\varnothing, 2}=0.4 v_{3, \varnothing}=0.2 v_{\varnothing, 3}=0.7$, and $I_{2,3}=0.8$, the other coefficients being equal to

0.

Thus, for the situation $P_{1}=0.5, P_{2}=0.25, P_{3}=-0.75$, the formula (2) becomes:

${ }^{A g} C I\left(P_{1}, P_{2}, P_{3}, P_{4}\right)=P_{A g}=0.5 \times 0.3+0.25 \times(0.1-0.3)-0.75 \times 0.3+0.8 \times \max (-0.5,0)=-0.15$

After executing one action plan that improves the performances for time between order and product manufacturing and accuracy of shipments but that degrades the performance for the average delay of shipments, we obtain $\mathrm{P}^{\prime}{ }_{1}=-0.25, \mathrm{P}_{2}=0.50$ and $\mathrm{P}_{3}=-0.25$. Applying formula (2) gives $P_{A g}^{\prime}=-0.10$. Therefore, the second situation is slightly better, which is consistent with the preceding rules.

\section{CONCLUDING REMARKS}

The analysis presented in this article deals with the evaluation of industrial performance, and especially with the question of performance aggregation to be raised by performance measurement systems.

A characterization of this problem has been given, highlighting the need to differentiate two main kinds of elementary performance evaluation: unipolar and bipolar ones. In addition, the problems of horizontal interactions between elementary expressions being not handled by the conventional weighted mean, the 2-additive Choquet integral and its generalized bipolar form have been proposed and used on two situations issued from an industrial case. The determination of the aggregation operator has been done from managers' expertise.

Nevertheless, the use of this advanced approach requires to explicitly define pieces of information aimed at aiding the decision-maker by a better understanding of the contribution of the elementary performances to the aggregated one, and at a better assessing of the different ways of improving the aggregated performances. In this perspective, further exploration of the meaning of the neutral performance value and of the practical conditions 
leading to a common or a separate processing of positive and negative performance values remains to be done. 


\section{REFERENCES}

[1] Neely A., Gregory M., Platts K. Performance measurement system design: a literature review and research agenda. Int. J. of Operations Production Management, 1995, 15 (4), 80116.

[2] Bititci U.S., Modelling of performance measurement systems in manufacturing enterprises, Int. J. of Production Economics, 1995, 42, 137-147.

[3] Neely A., The performance revolution: why now and what next? Int. J. of Operations and Production Management, 1999, 19 (2), 205-228.

[4] Kueng P., Krahn A.J., Building a Process Performance Measurement System: Some Early Experiences, J. of Scientific and Industrial Research, 1999, 58, 149-159.

[5] Ghalayini A.M., Noble J.S., Crowe T.J., An integrated dynamic performance measurement system for improving manufacturing competitiveness, Int. J. of Operations and Production Management, 1997, 15, pp. 80-116.

[6] Krause O., Mertins K., 1999, Performance management. Proc. of the International Conference on Advances in Production Management Systems, Berlin, Germany, 243-251.

[7] Berrah L., Mauris G., Vernadat F. Information aggregation in industrial performance measurement: rationales, issues and definitions. Int. J. of Production Research, 2004; 42 (20): 4271-4293.

[8] Grabot B., Objective satisfaction assessment using neural nets for balancing multiple objectives, Int. J. of Production Research, 1998, 36 (6), 2377-2395.

[9] Suwignjo P., Bititci U.S., Carrie A.S., Quantitative models for performance measurement system. Int. J. of Production Economics, 2000, 64 (1-3), 231-241.

[10]Rangone A. An analytical hierarchy process framework for comparing the overall performance of manufacturing departments, Int. J. of Operations and Production Management, 1996, 16 (8), 104-119. 
[11]Le Clainche J.F., Balanced scorecards et autres méthodes pour évaluer le score d'une entreprise, in Indicateurs de Performance (C. Bonnefous and A. Courtois, Eds.), Paris Hermès, 2001, 257-281.

[12]Berrah, L., Mauris, G., Foulloy, L., Haurat, A., Global vision and performance indicators for an industrial improvement approach, Computers in Industry, 2000, 43, 211-225.

[13]Bana e Costa C.A., Vansnick J.C. Applications of the MACBETH approach in the framework of an additive aggregation model. Journal of Multi-Criteria Decision Analysis, 1997, $6(2), 107-114$.

[14]Clivillé V., Berrah L., Mauris G. Quantitative expression and aggregation of performance measurements based on the MACBETH multi-criteria method. Int. J. of Production Economics, 2006, In press.

[15]Grabisch M., Roubens, M., Application of the Choquet integral in multi-criteria decision making, in Fuzzy Measures and Integrals: Theory and Applications (M. Grabisch, T. Murofushi, M. Sugeno Eds), New-YorkPhysica-Verlag, 2000, 348-374.

[16]Clivillé V., Berrah L., Mauris G., Information fusion in industrial performance: a 2-additive Choquet integral based approach, Proc. of IEEE Int. Conf. on Systems, Man and Cybernetics SMC 04, La Haye, Pays-Bas, CD-ROM, 2004, 6 pages.

[17]Grabisch M., Labreuche C. Fuzzy measures and integrals. In MCDA. Multiple Criteria Decision Analysis. Figueira J., Greco S. Ehrgott M. (eds). Kluwer Academic Publishers, 2004, 563-608.

[18]M. Grabisch and Ch. Labreuche, Bi-capacities --- Part I: definition, Möbius transform and interaction. To appear in Fuzzy Sets and Systems, 151 (2005), 211-236.

[19]M. Grabisch and Ch. Labreuche, Bi-capacities --- Part II: the Choquet integral. Fuzzy Sets and Systems, 151 (2005), 237-259. 


\section{List of Figures}

Figure 1. Performance structure of the strategic service rate objective

\section{List of Tables}

Table 1: Operational performance measurements

Table 2: Operational performance measurements and evaluations

Table 3: The weights of the different operational criteria

Table 4: The interactions between the operational criteria versus the tactical objective TBOP 


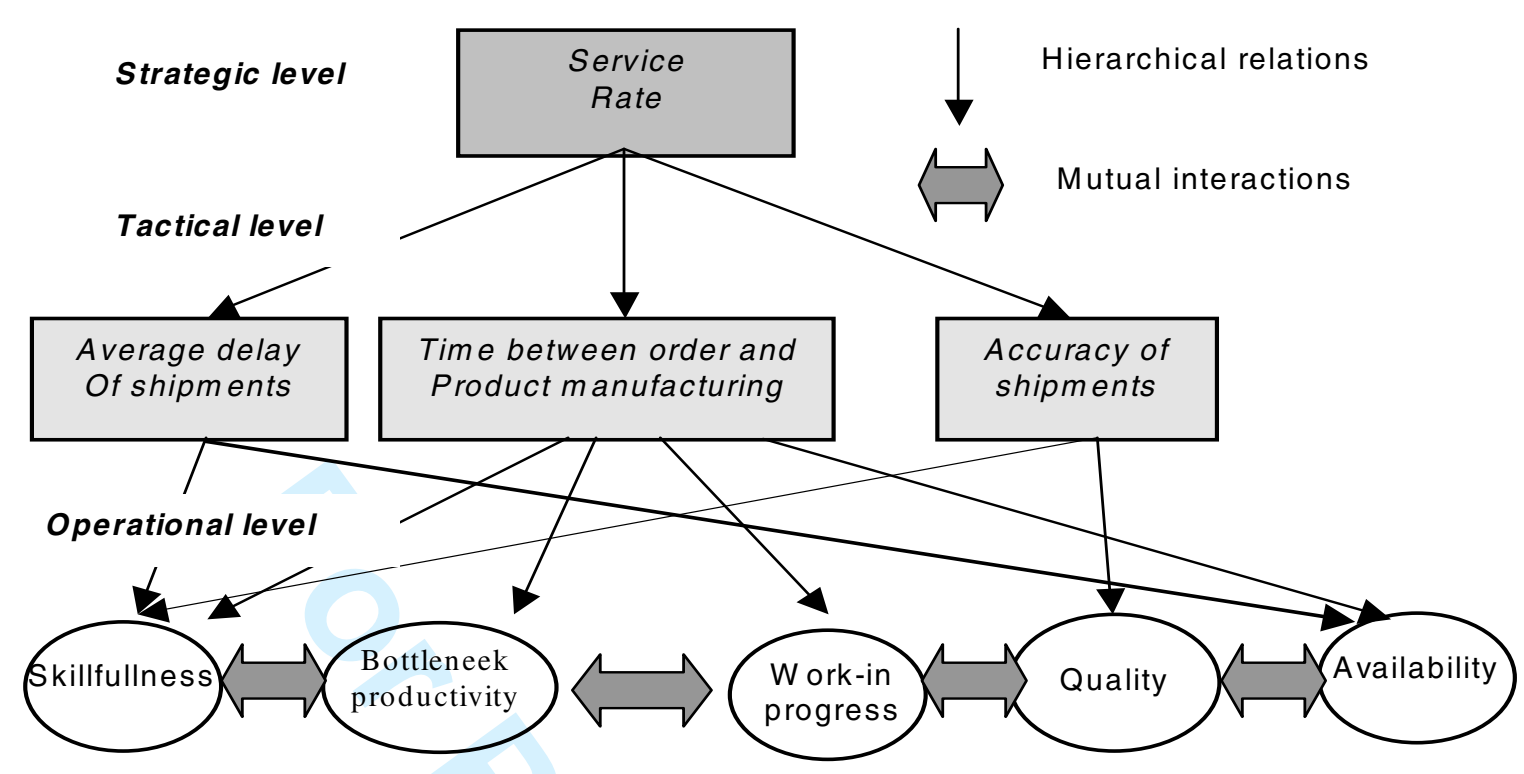

Figure 1. Performance structure of the strategic service rate objective 


\begin{tabular}{|l|c|}
\hline Operational & Performance Measurements \\
\hline Skillfulness & $p m_{S}=\frac{\text { number of operators able to work per equipment }}{\text { number of equipment }}$ \\
\hline Bottleneck & $p m_{\mathrm{BP}}=$ number of parcels manufactured, per hour, by the assembly activity \\
\hline Productivity & $p m_{\mathrm{WIP}}=$ duration of the work in progress \\
\hline Progress & $p m_{\mathrm{EA}}=\frac{\text { up time }+ \text { waiting time }}{\text { Ond }}$ \\
\hline Equipment & \\
\hline
\end{tabular}

Table 1: Operational performance measurements

\begin{tabular}{|c|c|c|}
\hline $\begin{array}{l}\text { Operational } \\
\text { indicators }\end{array}$ & $\begin{array}{l}\text { Performance Measurements } \\
\text { expected and current }\end{array}$ & $\begin{array}{l}\text { Performance Evaluations } \\
\text { expected/current }\end{array}$ \\
\hline Skillfulness & $\mathrm{pm}^{\mathrm{e}}=1.5 \mathrm{op} / \mathrm{eq} \mathrm{pm}^{\mathrm{c}}=1 \mathrm{op} / \mathrm{eq}$ & $p e^{e}=1 \quad p e^{c}=-1$ \\
\hline $\begin{array}{l}\text { Bottleneck } \\
\text { productivity }\end{array}$ & $\mathrm{pm}^{\mathrm{e}}=60 \mathrm{p} / \mathrm{h} \quad \mathrm{pm}^{\mathrm{c}}=50 \mathrm{p} / \mathrm{h}$ & $\mathrm{pe}^{\mathrm{e}}=1 \quad \mathrm{pe}^{\mathrm{c}}=-0.1$ \\
\hline $\begin{array}{l}\text { Work In } \\
\text { Progress }\end{array}$ & $\mathrm{pm}^{\mathrm{e}}=0.5$ week $\mathrm{pm}^{\mathrm{c}}=1.5$ week & $p e^{e}=1 \quad p e^{c}=0.5$ \\
\hline $\begin{array}{l}\text { Equipment } \\
\text { Availability }\end{array}$ & $\mathrm{pm}^{\mathrm{e}}=95 \% \quad \mathrm{pm}^{\mathrm{c}}=90 \%$ & $p e^{e}=1 \quad p e^{c}=0.2$ \\
\hline
\end{tabular}

Table 2: Operational performance measurements and evaluations 


\begin{tabular}{|l|c|}
\hline $\begin{array}{c}\text { Operational/tactical } \\
\text { criteria }\end{array}$ & $\begin{array}{c}\text { Time between order } \\
\text { and product manufacturing }\end{array}$ \\
\hline Skillfulness (1) & 0.20 \\
\hline Bottleneck & 0.35 \\
productivity (2) & \\
\hline $\begin{array}{l}\text { Work In } \\
\text { Progress (3) }\end{array}$ & 0.35 \\
\hline Equipment & 0.10 \\
\hline Availability (4) & \\
\hline
\end{tabular}

Table 3: The weights of the different operational criteria

\begin{tabular}{|l|c|c|c|c|}
\hline & Skillfulness & $\begin{array}{c}\text { Bottleneck } \\
\text { Productivity }\end{array}$ & $\begin{array}{c}\text { Work } \\
\text { in Progress }\end{array}$ & $\begin{array}{c}\text { Equipment } \\
\text { Availability }\end{array}$ \\
\hline Skillfulness & & 0.07 & 0.13 & 0.07 \\
\hline Bottleneck & 0.07 & & -0.08 & -0.06 \\
\hline productivity & 0.13 & -0.08 & & 0 \\
\hline Work In & & & & \\
\hline Progress & 0.07 & -0.06 & 0 & \\
\hline Equipment & & & & \\
\hline
\end{tabular}

Table 4: The interactions between the operational criteria versus the tactical objective TBOP 